\title{
IAU Symposium on Access to Higher Education Amman, 21-24 November 1988
}

IAU, in collaboration with the Association of Arab Universities (AArU), is organizing a Symposium to address the problem of access to higher education - one of the most complicated issues confronting educational policy-makers worldwide. Many approaches and questions could, therefore, be singled out for investigation. Those suggested for the Symposium are thus selective and limited, but it is hoped that they will address a number of the important aspects of the problems that have to be faced.

An international study of access to higher education was carried out by Dr. Frank Bowles ${ }^{1}$ in the early 1960 s, under the Joint UNESCO/IAU Research Programme in Higher Education. That period was almost universally one of rapid expansion in higher education, marked mainly by confidence and optimism. It was felt by some that this sweeping process of growth was bound to produce some turbulence as well as local and temporary breakdowns here and there in the system, but no one really foresaw the two major but quite different crises that were to affect higher education in the following decade: first, the wave of student "unrest" that spread across many regions of the world and culminated in the year 1968 and, second, the economic and financial crisis which started in the 1970 s and from which the world has not yet completely recovered. The higher education scene has therefore changed profoundly since 1963 when the Bowles study was first published, and although problems of access have since been constantly under review, particularly at a national level, the time has come to undertake a new international survey of problems and solutions in this field.

The Symposium is to take place at the University of Jordan in Amman and will convene some 80 to 100 experts from a similar number of countries around the world, thus assuring universality with regard to input and perspective.

IAU will prepare a general introduction to the Symposium to provide a broad analysis of the issues at stake and of some of the factors that have shaped or influenced policies of access in recent years.
Three main topics will be examined:

1. Who determines the policies of access and their objectives? This will include questions concerning the autonomy of institutions of higher education themselves, the role of governments in determining access policies and the important factor of public opinion as an influence on access policy.

2. How are the policies of access implemented? Attention will be focused on the distribution and allocation of financial resources, which are obviously powerful instruments for the implementation of particular access policies.

3. What are the special problems concerning foreign students a major concern of universities throughout the world? At least three sets of problems will be examined:

A. How can sending countries and institutions best identify and select the receiving countries/institutions most likely to meet their needs adequately? What kind of information systems would be most effective for the users in both sending and receiving countries, and how could access to such systems be achieved?

B. How should sending and receiving countries/institutions try to adjust and harmonize their respective policies as to the admission of students and the recognition of studies, diplomas and degrees? How does dependence on foreign training for undergraduate or postgraduate students affect national higher education policy?

C. How can the smooth and effective reintegration of students after their return from abroad best be assured and the undesirable effects of a "brain drain" be avoided? Are potential political and cultural effects of long sojourns abroad balanced by the educational benefits to the student and his or her society?

\section{REFERENCES}

1. Bowles, F., (1963) The International Study of University Admissions, Vol.1: Access to Higher Education, Unesco and IAU. 